\title{
Efeitos de Instruções Sobre Respostas de Checagem ${ }^{1}$
}

\author{
Paulo Roberto Abreu ${ }^{2}$ \\ Maria Martha Costa Hübner \\ Universidade de São Paulo
}

\begin{abstract}
RESUMO - O estudo teve o objetivo de testar o controle verbal de diferentes instruções sobre respostas de checagem. Dois participantes adultos foram instruídos a separar quatro tipos de sementes misturadas. Utilizou-se um delineamento sujeito único ABCA na apresentação das instruções. Os resultados mostraram que a instrução C com descrição de conseqüências aversivas aumentou a freqüência das respostas de checagem, sendo que o participante um o fez em relação à instrução B com autoclítico e o participante dois em relação à instrução $\mathrm{A}$ de linha de base. Na fase de reversão ambos os participantes diminuíram a freqüência após a apresentação de uma instrução A sem descrição de conseqüências aversivas. Sugere-se que a instrução C especificando toda a contingência pode ter estabelecido função aversiva para as respostas de separação não-efetivas.
\end{abstract}

Palavras-chave: respostas de checagem; comportamento governado por regras; autoclítico; transtorno obsessivo-compulsivo.

\section{Effects of Instructions on Checking Responses}

\begin{abstract}
The study had the objective of testing the verbal control of different instructions on checking responses. Two adult participants were instructed to separate four types of mixed seeds. An ABCA single-subject design was used in the presentation of the instructions. The results showed that instruction $\mathrm{C}$ with description of aversive consequences increased the frequency of checking the responses. Participant one showed an increase in relation to instruction B with autoclitic and participant two in relation to instruction $\mathrm{A}$ of the base line. In the reversion phase both participants reduced the frequency after the presentation of an instruction A without description of aversive consequences. The results suggest that instruction $\mathrm{C}$ that specifies the whole contingency established an aversive function for the non-effective separation responses.
\end{abstract}

Keywords: checking responses; rule-governed behavior; autoclitic; obsessive-compulsive disorder

O aprendizado por regras é importante, pois o comportamento por elas especificado pode ser aprendido mais rapidamente, proporcionando com isso algumas vantagens adaptativas, dentre elas a preservação dos indivíduos de nossa espécie em muitas situações de perigo (Skinner, 1974/1976). Assim as pessoas de uma determinada comunidade ensinam a seus membros habilidades importantes, sem que esses necessitem aprender diretamente por meio das contingências descritas pelas regras. Segundo Skinner (1974/1976) regras são estímulos especificadores de contingências, tendo função de estímulo discriminativo para o seu seguimento. $\mathrm{O}$ autor cunhou o termo comportamento governado por regras para diferenciá-lo do comportamento sob controle direto das contingências. É possível dizer que um comportamento é governado por regra quando o comportamento que se segue à regra é o comportamento especificado por ela, ocorrendo na sua presença.

Uma regra na função de antecedente verbal pode descrever o desempenho requerido do ouvinte sem fazer qualquer alusão às conseqüências de seu não-seguimento (Catania,

1 Apoio: CNPq. O primeiro autor agradece a H. S. Toda Comércio de Cereais, em especial ao colega Wilson Tchuki Toda por ter cedido os materiais e instalações da loja para a coleta de dados. Agradecimentos são estendidos também a psicóloga Juliana Helena Silvério pela ajuda cuidadosa na coleta.

2 Endereço para correspondência: Rua Rio Grande do Sul, 199, apto. 14 A. Bairro: Água Verde. Curitiba, PR. CEP: 80620-080. Fone/fax: (41) 3244-6653 e (41)9223-3702.E-mail: pauloabreu@usp.br
2003; Catania, Matthews, \& Shimoff, 1982). Nesses moldes uma regra pode ser observada em formulações que descrevem somente o comportamento a ser seguido, como quando um falante diz "pare", "não faça assim" ou "saia". De outro modo, a regra pode especificar toda a contingência com sua conseqüência, a exemplo de alguém a quem é dito o que acontecerá se não disser ou fizer algo (Catania, 2003; Catania et al., 1982). As pessoas frequentemente optam por descrever as contingências que estão operando em determinado ambiente quando solicitam mais enfaticamente comportamentos apropriados ao outro. Dessa forma, por exemplo, as agências controladoras freqüentemente promovem o seguimento de regras através da especificação de conseqüências aversivas a curto, médio e longo prazo do seu não seguimento (Sidman, 1989/2001; Skinner 1953/1968). A ameaça do inferno para os comportamentos pecaminosos ou as placas de trânsito que trazem avisos de multa para as infrações, normalmente observados em igrejas e governo respectivamente, são exemplo de regras que podem especificar os três termos da tríplice contingência ${ }^{3}$.

$\mathrm{Na}$ análise das funções que podem assumir as regras observa-se a multiplicidade de possibilidades, não estando essas circunscritas unicamente à função de estímulo discri-

3 Segundo Matos (2001) o termo regra frequentemente tem sido usado para descrever uma variedade de circunstâncias antecedentes e de respostas, embora estudos recentes tragam a expressão instruções para especificar as circunstâncias em que acontece a ação. Similarmente a abordagem da autora, o presente estudo utilizará os dois termos indistintamente. 
minativo (Albuquerque, 2001). Alguns autores afirmam que as regras poderiam modificar a função de outros estímulos (Braam \& Malott, 1990; Blakely \& Schlinger, 1987; Malott, 1988; Schlinger \& Blakely, 1987).

Para Schlinger e Blakely (1987) as regras seriam estímulos alteradores de função por modificarem a função de estímulos não-verbais por elas descritos, produzindo com isso mudanças no comportamento evocado. Mas segundo a conceituação de Schlinger e Blakely (1987), o efeito evocativo estaria residindo no estímulo discriminativo descrito na regra, não na regra em si, como descreve a conceituação skinneriana. Em uma outra interpretação pautada na modificação da função de estímulo, regras poderiam ser entendidas como sendo operações estabelecedoras (OE) devido a sua propriedade de aumentar a efetividade de algum objeto ou evento como reforçador para o seu seguimento, além de evocar qualquer comportamento que tenha produzido dado reforçador no passado (Malott, 1988; Malott, 1989). Contingências de controle aversivo normalmente são bons exemplos de OE por aumentarem o valor da suspensão da estimulação aversiva e por evocarem os comportamentos de fuga ou esquiva (Michael, 1982; 1993; 2000). Uma instrução que descreva o comportamento a ser seguido pelo ouvinte, sinalizando conseqüências aversivas para o não seguimento, poderia preencher esses critérios. Assim, a instrução "se você não tirar as roupas do varal elas vão molhar na chuva”, estabeleceria o comportamento de não seguimento da regra e sua conseqüência como uma condição aversiva. O seguimento da regra suspenderia ou reduziria automaticamente a aversividade. Um possível seguimento nesse contexto seria o ouvinte retirar a roupa do varal em um comportamento de esquiva. Determinada regra evocaria o seu seguimento atenuando com isso a aversividade para o não seguimento (Braam \& Malott, 1990; Malott, 1988; Malott, 1989).

O estudo básico do comportamento governado por regras é interessante também para a clínica, pois algumas implicações conceituais podem ser transpostas na análise dos contextos relacionados as síndromes comportamentais. No transtorno obsessivo-compulsivo (TOC), por exemplo, clientes mostram comportamentos repetitivos de checagem que supostamente estariam sob o controle de auto-regras. Subtipos de indivíduos com o diagnóstico, chamados de "checadores", parecem apresentar essa relação R-R entre pensamentos e comportamentos abertos. Nela o primeiro elo da díade (R-R) seria constituído pelas auto-regras trazidas nos "pensamentos obsessivos" e o segundo elo pelo comportamento governado por regras, normalmente concebido na literatura como sendo constitutivo das "compulsões" (Abreu \& Prada, 2004, 2005; Zamignani, 2001). De acordo com essa conceituação clássica os indivíduos poderiam apresentar compulsões de checagem sob o controle de obsessões relacionadas às regras descritoras de responsabilidade pessoal, como em uma auto-instrução em que um participante diz a si mesmo que sua família correrá perigo se não conferir a válvula do gás. A checagem controlada por regras ocorreria por meio de respostas repetidas cuja função seria esquivar algum evento aversivo conseqüente a um comportamento inefetivo em produzir mudanças específicas no ambiente.

Algumas explicações cognitivistas enfatizam o papel singular dos pensamentos do obsessivo-compulsivo no desenvolvimento, manutenção e modificação das checagens (Rachman, 2002). O modelo enfatiza a relação causal R-R como sendo uma explicação útil no entendimento do fenômeno clínico. Estudos experimentais orientados por essa matriz teórica mostram que uma forma efetiva de levar alguém a apresentar comportamentos de checagem é apresentar instruções descritoras de conseqüências negativas que atribuem excessiva responsabilidade na execução de uma tarefa (Arntz, Voncken, \& Goosen, 2007; Bouchard, Rhéaume, \& Ladouceur, 1999; Ladouceur, Rhéaume, \& Aublet, 1997; Ladouceur et al., 1995; Lopatka \& Rachman, 1995; Mancini, D’Olimpio, \& Cieri, 2004). Responsabilidade é definida dentro da hipótese cognitiva como uma crença que alguém traz de possuir um poder de provocar ou prevenir conseqüências negativas cruciais (Salkovskis, Richards, \& Forrester, 1995). Determinadas conseqüências podem ser concretas ou morais (Salkovskis, 1995), dito de outra forma, contingenciais ou apenas descritas pelas regras sociais. Esse conceito enfatiza duas "distorções cognitivas" relacionadas: a influência pessoal e as conseqüências negativas. Uma conseqüência negativa seria um evento cuja probabilidade de ocorrência dependeria ou não do comportamento do indivíduo. Por seu turno, a influência pessoal seria a percepção do indivíduo sobre o seu papel causal na produção do evento.

Em um estudo em especial, Ladouceur et al. (1997) testaram o efeito da variável influência pessoal e das conseqüências negativas em situações de tomada de decisão em adultos. $\mathrm{O}$ objetivo do delineamento seria tentar isolar a variável crítica na determinação das checagens. No experimento, setenta e sete participantes adultos foram divididos em quatro amostras não clínicas, sendo orientados a separar pílulas coloridas misturadas. Foram empregadas duzentas pílulas de diferentes cores (onze tipos, vinte pílulas de cada) e quinze garrafas semi-transparentes. Como instrução geral o experimentador dizia que o grupo de pesquisa havia sido contratado por uma companhia farmacêutica para realizar um estudo relacionado à exportação de uma nova droga para combater um vírus que estava devastando um país na Ásia. As amostras foram dispostas em quatro condições experimentais: Condição Combinada, Condição de Influência, Condição de Conseqüências Negativas e Condição de Controle.

$\mathrm{Na}$ Condição Combinada era apresentada uma instrução para separação orientando os participantes a fazê-lo com cuidado, pois assim poderiam prevenir sérias conseqüências já que o resultado da tarefa influenciaria diretamente a manufatura das drogas. Com o objetivo de aumentar a influência pessoal, na Condição de Influência, foi adicionada às instruções da condição combinada a informação de que os participantes eram parte de uma pequena amostra de três pessoas e que devido a isso seu trabalho teria influência direta na tarefa. $\mathrm{Na}$ Condição de Conseqüências Negativas as instruções gerais da condição combinada foram apresentadas, exceto que, com o objetivo de reduzir a influência pessoal, foi dito aos participantes que eles compunham uma equipe de dois mil participantes que levantariam dados para as conclusões do estudo. Na Condição de Controle apenas foi esclarecido que a fase era ainda uma situação de treino, portanto sem nenhuma conseqüência já que os resultados não seriam analisados. 
As variáveis dependentes foram medidas por observação direta, por questionários e inventários. Para medição das repostas de checagem, quatro topografias foram então categorizadas: (1) Hesitações, definidas como a observação atenta da garrafa por $2 \mathrm{~s}$ ou mais, ou como o movimento das mãos do participante entre duas pílulas diferentes por pelo menos 2s; (2) conferências e modificações durante a tarefa, definidas como a interrupção da separação em uma determinada garrafa, por aproximadamente $1 \mathrm{~s}$, com o despejamento para observação do seu interior. Na condição 2 o esvaziamento do conteúdo da garrafa na palma da mão foi contabilizado. (3) O número de erros ocorridos durante a tarefa foi também medido; e por fim, (4) o tempo demandado na classificação. No estudo, foi ainda solicitado aos participantes que preenchessem questionários e inventários para avaliação de "respostas subjetivas". Ao final da sessão o experimentador revelava o experimento solicitando a assinatura em termo de consentimento.

Os resultados do estudo mostraram que a influência pessoal é o melhor preditor da percepção da responsabilidade. $\mathrm{O}$ aumento do potencial das consequiências negativas foi suficiente para iniciar algumas topografias relacionadas a hesitações nos participantes, mas a combinação da influência e das conseqüências negativas foi necessária para produzir comportamentos de checagem. Ao discutirem os resultados os autores concluíram que "ainda que a probabilidade e severidade da conseqüência negativa estejam relacionadas à responsabilidade, seus efeitos foram menos acentuados" (Ladouceur et al., 1997, p. 426).

Conforme sinaliza De Rose (1999), apesar de assumirem entidades iniciadoras do comportamento, portanto internas ao organismo, as teorias mentalistas só podem inferir essas entidades a partir de eventos comportamentais e por isso trazem dados que podem ser de interesse para a análise experimental do comportamento. As explicações cognitivas para os dados levantados no estudo supracitado enfatizam que os comportamentos de checagem ocorrem quando os indivíduos trazem "crenças" relacionadas à responsabilidade aumentada para prevenir danos (Ladouceur et al., 1997). Por esse motivo elas se mostram ainda bastante especulativas, já que os experimentos aferiram apenas o efeito produzido pela apresentação de instruções com descrição de conseqüências aversivas, no caso da concepção cognitiva, a descrição de "responsabilidade pessoal aumentada" e das "conseqüências negativas".

Para Matos (2001) posturas interpretativas cognitivas compreendem que o comportamento é controlado por processos simbólicos localizados na consciência ou mente. Afirma a autora que no behaviorismo radical tanto a linguagem, os processos simbólicos e as regras são comportamento verbal, gerados no ambiente social. O comportamento governado por regras seria portanto sub-produto da interação social e não causa de outros comportamentos.

O estudo de Ladouceur et al. (1997) investigou as relações de instruções e seu seguimento em delineamentos de grupo empregando inventários e análises de dados estatísticas (MANOVA), com comparações entre os grupos experimental e controle. O experimento proposto foi feito a partir do estudo de Ladouceur et al. (1997), utilizando também instruções com descrições de conseqüências aversivas. Contudo não se teve o objetivo de replicar diretamente ou sistematicamente o procedimento adotado. No presente, utilizou-se um delineamento de sujeito como seu próprio controle, com fases experimentais de levantamento de linha de base e reversão. No estudo foi investigado também o efeito de outros tipos de instruções no controle da resposta de checagem (e.g., empregando um operante autoclítico).

\section{Método}

\section{Participantes e ambiente experimental}

Dois participantes adultos do sexo feminino, verbalmente habilidosos, com 33 e 28 anos. Os participantes foram convidados por terceiros a trabalhar em uma tarefa de separação de sementes, sendo conduzidos até uma loja de cereais. $\mathrm{Na}$ ocasião do convite, foi instruído que o trabalho demandaria uma hora e que ganhariam $\mathrm{R} \$ 30,00$ ao final da tarefa. Os participantes realizaram a separação das sementes em uma mesa no centro do primeiro andar. Esse andar era constituído de sacarias com vários cereais distribuídos no espaço físico de $99 \mathrm{~m}^{2}$ da loja. A mesa de coleta estava disposta ao lado do balcão de atendimento, logo abaixo da câmera de vídeo própria do estabelecimento. A coleta aconteceu em um domingo estando a loja fechada para os clientes. Para separação foram utilizados quatro potes de plástico semitransparentes com capacidade para dois litros. Quatro tipos de sementes de cores e dimensões semelhantes foram misturados em um saco plástico próprio para transporte: Feijão Bolinha, Feijão Fradinho, Grão de Soja e Tremoço Achatado. As sementes encontravam-se misturadas em igual proporção, somando um peso total de $3,3 \mathrm{Kg}$. Com exceção da primeira instrução feita pessoalmente, as outras instruções foram passadas por telefone pelo experimentador que permaneceu no andar superior. A separação das sementes foi assistida em tempo real e gravada pela câmera da loja.

Seguindo o modelo de Laudouceur et al. (1997) e de outros experimentos dessa área de investigação (Arntz et al., 2007; Bouchard et al., 1999; Ladouceur, Léger, Rhéaume, \& Dubé., 1996; Ladouceur et al., 1995; Lopatka \& Rachman, 1995; Mancini et al., 2004), somente ao final da sessão o experimentador revelou o estudo, explicando ao participante os objetivos e procedência da pesquisa com a solicitação de assinatura em termo de consentimento sobre o uso dos dados obtidos.

\section{Procedimento}

A sessão experimental teve duração de sessenta minutos, divididos em quatro fases de quinze minutos. O tempo da apresentação das instruções não foi contabilizado visto a variação na diferença no tamanho das sentenças. O cronômetro era iniciado ao final da apresentação da instrução e pausado ao término do tempo de cada fase. Utilizou-se um delineamento sujeito único $\mathrm{ABCA}$ disposto da seguinte forma:

Fase A / Linha de base - Foi apresentada pessoalmente a seguinte instrução para o participante - "Aqui estão qua- 
tro tipos de sementes nobres misturadas. Sua tarefa vai ser separar as quatro e colocá-las nesses quatro potes. Você terá uma hora para fazer isso. Eu vou estar em reunião lá e cima e por isso se precisar falar com você, farei pelo telefone".

Durante a separação foram contadas as respostas de checagem, definidas operacionalmente como verificação das sementes já separadas nos potes com função de se evitar erros. Na checagem as seguintes topografias de resposta foram registradas: a manipulação dentro do próprio pote, o despejar na mão ou mesa para nova conferência, o transferir as sementes erroneamente separadas de um pote para outro, o inclinar/mexer o pote para uma melhor visualização durante $2 \mathrm{~s}$ ou mais e a observação do pote por $2 \mathrm{~s}$ ou mais sem manipulação direta.

Fase B - Foi dada a seguinte instrução por telefone para o participante após 15 minutos transcorridos desde a instrução A - "Separe com muita atenção".

Aqui foi adicionado o autoclítico "muita" à instrução de separar com o objetivo de testar o controle verbal sobre o participante. $\mathrm{O}$ autoclítico é por definição uma unidade de comportamento verbal que depende de outro comportamento verbal para sua ocorrência, aumentando o controle daquela sobre o comportamento do ouvinte (Skinner, 1957/1992; Hübner, 2003; Hübner, Austin, \& Miguel, 2008). É por isso classificado como sendo um operante verbal de ordem superior (Borloti, 2004). Na fase B foi também registrado o $\mathrm{n}^{\circ}$ de respostas de checagem.

Embora a formulação verbal de B seja denominada de instrução com autoclítico para fins didáticos, ressalta-se que determinado operante só pôde ser assim classificado quando foi constatado o efeito autoclítico sobre o participante.

Fase C - Após 15 minutos transcorridos desde a instrução B, foi apresentada a seguinte instrução, via telefone, com descrição de conseqüências aversivas: "Na verdade esse lote tem um tipo de semente que está com uma quantidade grande de agrotóxico que pode dar diarréia nas pessoas que comerem. Como essa mistura será fornecida para a merenda das crianças de uma escola, é muito importante que você as separe com muita atenção".

Nessa fase foi adicionada a descrição de toda a contingência na instrução para a separação com o objetivo de testar o controle verbal sobre o participante. Foi então registrado $\mathrm{o} \mathrm{n}^{\circ}$ de respostas de checagem.

Fase A / Reversão - Após 15 minutos transcorridos desde a instrução C, foi apresentada a seguinte instrução, via telefone, sem descrição de conseqüências aversivas: "Eu e meu chefe vimos que esse lote que você está separando é um lote mais antigo que não tem as sementes contaminadas. Então é só você separar as sementes".

Nessa fase foi dada a instrução com o objetivo de promover a reversão para uma freqüência de respostas de checagem semelhantes à linha de base. Segundo Catania (1998/1999) “efeitos reversíveis são mudanças na performance que são eliminadas, imediatamente ou algum tempo depois, quando as operações que a produzem são descontinuadas (p.ex., se o responder retorna ao nível inicial após a punição, os efeitos da punição são reversíveis)" (p. 408). Sendo assim, o efeito da instrução C com a descrição de uma conseqüência aversiva com efeitos a longo prazo (e.g., "caso você não separe certo, crianças poderão ingerir sementes contaminadas") poderia estar sendo revertido com uma nova instrução, no caso a A, descritora da suspensão da conseqüência futura. Embora a primeira instrução A seja topograficamente diferente da última instrução $\mathrm{A}$, o critério que permite correlacioná-las no delineamento ABCA adotado é o efeito que essas exercerão sobre o participante. Portanto, preenche-se o critério funcionalmente-orientado para a reversão. $\mathrm{O} \mathrm{n}^{\circ}$ de respostas de checagem foi registrado nessa fase.

Após o final das fases o experimentador entrevistou pessoalmente os participantes com o objetivo de, se necessário, apenas complementar os dados empíricos. Foram feitas três perguntas, sendo elas: (a) "Depois do primeiro telefonema em que eu lhe pedi apenas que separasse com atenção, você acha que checou mais do que já havia checado no início da tarefa?"; (b) "Depois do segundo telefonema em que lhe contei sobre as sementes contaminadas, você acha que checou mais do que já havia checado na vez em que lhe fiz o primeiro telefonema?" (c) "Depois do terceiro telefonema em que lhe contei que seu lote era antigo e não estava contaminado, você acha que checou mais do que já havia checado na vez em que lhe fiz o segundo telefonema?".

As informações levantadas pela entrevista não foram o foco principal na análise dos dados visto a falta de controle do método. Por esse motivo seus dados foram muito pouco utilizados. Entrevistas freqüentemente permitem certo viés nas respostas verbais dos participantes devido ao múltiplo controle de estímulos envolvido. Alguns desses problemas podem ser evidenciados nas pesquisas sobre a correspondência entre o fazer e o relatar (Lloyd, 2002).

\section{Resultados}

A Figura 1 mostra as curvas acumuladas das respostas de checagem dos participantes 1 e 2 ao longo da sessões.

O participante 1 apresentou quatro respostas de checagem na linha de base, nenhuma na fase de instrução com autoclítico, três respostas após a instrução com descrição de conseqüências aversivas e zero emissões na fase de reversão. Durante a entrevista final o participante 1 relatou que após ter recebido a primeira instrução foi estudando até descobrir um método para separar as sementes que pudesse lhe trazer melhores resultados.

O participante 2 apresentou nenhuma checagem na linha de base, três na fase de instrução com autoclítico, quatro respostas após a instrução com descrição de conseqüências aversivas e uma emissão na fase de reversão. O participante 2 separou também em um canto da mesa as sementes pretas que não faziam parte da mistura e as sementes que julgou estarem estragadas.

A Figura 2 apresenta a comparação entre as freqüências de emissão de respostas de checagem entre os participantes 1 e 2 .

Ambos os participantes apresentam notória variabilidade inter-sujeitos em relação à freqüência de respostas de checagem. Como regularidades comportamentais, observou-se que os participantes aumentaram a freqüência dos comportamentos de checagem na fase $\mathrm{C}$, sendo que o participante 1 o fez em relação a fase B (instrução com autoclítico) e o participante 2 em relação à linha de base. Igualmente semelhante, na fase de reversão, ambos diminuíram a freqüência 


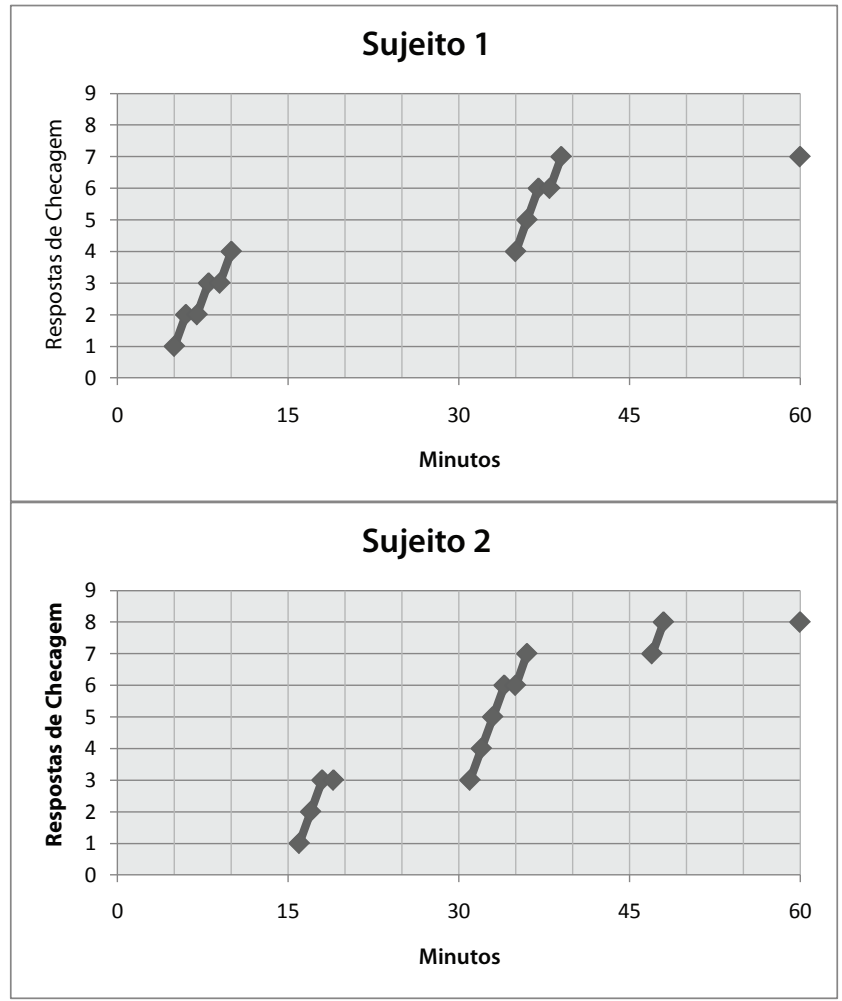

Figura 1. Curvas acumuladas das respostas de checagem dos participantes 1 e 2 no período total de 60 minutos da sessão experimental. O delineamento ABCA foi dividido em quatro períodos de 15 minutos. No $1^{\circ}$ minuto foi apresentada a primeira instrução referente à separação das sementes (Fase A); após 15 minutos transcorridos desde a instrução $\mathrm{A}$, foi apresentada a instrução com autoclítico (Fase B); após 15 minutos transcorridos desde a instrução B, foi apresentada a instrução com descrição de conseqüências aversivas (Fase C); e após 15 minutos transcorridos desde a instrução C, foi apresentada a instrução sem descrição de conseqüências aversivas (Fase A). O tempo total da sessão exclui as pausas no cronômetro no momento da apresentação das instruções. após apresentação da instrução sem descrição de conseqüências aversivas. $\mathrm{O}$ participante 1 apresentou reversão total e o participante 2 reversão parcial, conforme definição de Catania (1998/1999).

\section{Discussão}

A análise experimental do comportamento tem demonstrado que a especificação de toda a contingência na instrução parece controlar as respostas não-verbais dos participantes, efeito demonstrado em estudos que manipularam regras com anúncio de conseqüências reforçadoras (Braam \& Malott, 1990; Mistr \& Glenn, 1992; Reitman \& Gross, 1996). Similarmente também aos dados obtidos no estudo de Ladouceur et al. (1997), observou-se no presente estudo que a instrução com descrição de conseqüências aversivas controlou os comportamentos de checagem em ambos os participantes.

Para Malott (1988) as conseqüências próximas seriam as verdadeiras responsáveis, ao menos inicialmente, pelo controle instrucional. Segundo o autor, determinadas contingências atuariam diretamente como reforço negativo ou punição. A instrução dada pelo experimentador na fase $\mathrm{C}$ descreveu a conseqüência para uma separação não-efetiva das sementes. A especificação de toda a contingência funcionou como uma operação que estabeleceu o valor aversivo para o comportamento inefetivo, sendo este decorrente de um não seguimento da regra. Essa condição aversiva aprendida provavelmente é o resultado de uma história de punição nas situações em que houve falha na aquiescência de certas classes gerais de regras (Malott, 1988). Para esquivar o evento aversivo, os participantes precisaram simplesmente seguir a instrução, sendo, portanto, reforçados com a suspensão da provável conseqüência negativa e com a diminuição automática dos

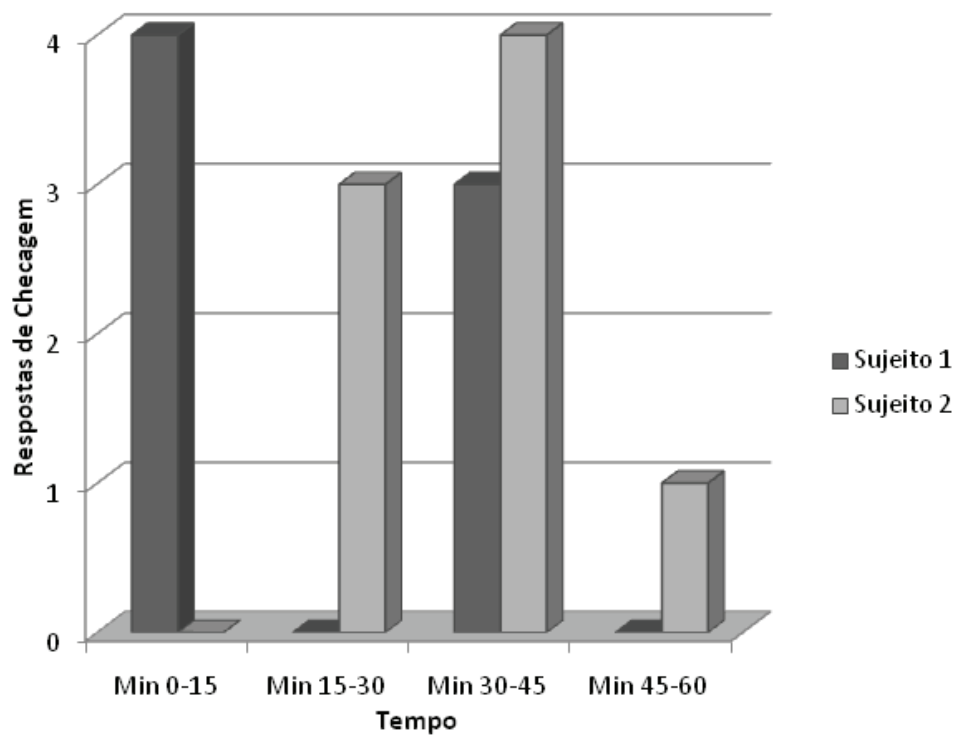

Figura 2. Comparação entre as freqüências de emissão de respostas de checagem entre os participantes 1 e 2 durante a sessão experimental. O delineamento ABCA foi dividido em quatro períodos de 15 minutos - De 0-15 minutos foi medido o efeito da primeira instrução referente à separação das sementes (Fase A); de 15-30 minutos foi medido o efeito da instrução com autoclítico (Fase B); de 30-45 minutos foi medido o efeito da instrução com descrição de conseqüências aversivas (Fase C); e de 45-60 minutos foi medido o efeito da instrução sem descrição de conseqüências aversivas (Fase A). O tempo total da sessão exclui as pausas no cronômetro no momento da apresentação das instruções. 
sentimentos de medo ou culpa (Malott, 1988). O seguimento das instruções pode ser evidenciado através do aumento da freqüência das respostas de checagem. Dadas respostas teriam a função de evitar os erros na separação das sementes.

Analisando os resultados isoladamente, observa-se que o participante 1 apresentou quatro respostas de checagem durante a fase de linha de base. Esse resultado aparentemente contradiz os resultados de alguns estudos sobre o comportamento governado por regras, onde as instruções que descreviam apenas a resposta esperada do ouvinte exerceram fraco controle sobre seu seguimento (Braam \& Malott, 1990; Mistr \& Glenn, 1992; Reitman \& Gross, 1996). Contudo, o participante 1 relatou na entrevista que variou seu comportamento até descobrir um método mais efetivo para separar as sementes. É possível então que as checagens verificadas nessa fase estivessem então ocorrendo mais sob o controle da própria contingência do que sob o controle da instrução A.

No estudo, outros dados de interesse foram verificados a partir do emprego dos autoclíticos. Na fase B, o operante verbal "muita" poderia ser classificado com sendo um autoclítico quantificador do operante verbal de primeira ordem, no caso o operante "atenção". Segundo Skinner (1957/1992) o autoclítico quantificador afeta o ouvinte por indicar propriedades relativas à quantidade do operante básico emitido pelo falante. No experimento o efeito autoclítico modificou a reação do participante 2 na tarefa de separação das sementes. Esse participante apresentou um aumento na freqüência das respostas de checagem. Mas é interessante notar que, contrariamente ao efeito esperado, o participante 1 não apresentou respostas de checagem na apresentação da instrução. Não foi observado o aumento na freqüência das checagens em relação à fase de linha de base, fato que impediria até mesmo a identificação dessa instrução como tendo um operante autoclítico. Uma interpretação para o fraco controle pode residir no histórico de reforçamento da correspondência entre a instrução com a formulação verbal autoclítica e o comportamento de seguimento do participante. Essa interpretação ainda é especulativa, sugerindo novas pesquisas sobre o histórico de reforçamento do seguimento de regras com operantes verbais de ordem superior.

Ladouceur et al. (1997) estenderam a pertinência dos dados do seu experimento para a análise de alguns fenômenos clínicos, como o transtorno obsessivo-compulsivo (TOC). A despeito da circularidade explicativa trazida na discussão causal cognitiva (Skinner 1953/1968), o tipo de estudo proposto por Ladouceur et al. (1997) é bastante instigante, podendo por isso ser revisitado por analistas experimentais do comportamento em estudos posteriores. O presente experimento apresentou algumas limitações devido ao número de participantes adotados e pela variabilidade encontrada nas freqüências das respostas de checagem. Esse fato impediria a generalidade dos dados obtidos. Contudo algumas regularidades comportamentais foram encontradas em ambos os participantes como o aumento de freqüência das checagens na fase $\mathrm{C}$ (em relação à fase $\mathrm{B}$ para o participante 1 e à fase A para o participante 2) e como a diminuição na fase de reversão. Novas pesquisas nesse campo serão necessárias na identificação mais precisa das variáveis experimentais. Uma metodologia como a de sujeito único pode ter o potencial de especificar quais são os processos envolvidos no controle de certos tipos de regras sobre as respostas de checagem.

\section{Referências}

Abreu, P. R., \& Prada, C. G. (2004). Transtorno de ansiedade obsessivo-compulsivo e transtorno da personalidade obsessivocompulsivo: um "diagnóstico" analítico-comportamental. Revista Brasileira de Terapia Comportamental e Cognitiva, 6(2), 211-220.

Abreu, P. R., \& Prada, C. G. (2005). Relação entre os condicionamentos operante e respondente no transtorno obsessivo-compulsivo. Revista Estudos de Psicologia, 22(3), 225-232.

Albuquerque, L. C. (2001). Definições de regras. In H. J. Guilhardi, M. B. B. P. Madi, P. P. Queiroz, \& M. C. Scoz (Eds.), Sobre comportamento e cognição. Expondo a variabilidade (pp.132140). Santo André: ESETec.

Arntz, A., Voncken, M., \&, Goosen, A. C. A. (2007). Responsibility and obsessive-compulsive disorder: an experimental test. Behavioral Research and Therapy, 45, 425-435.

Blakely, E., \& Schlinger, H. (1987). Rules: function-altering contingency-specifying stimuli. The Behavior Analyst, 10, 183-187.

Bouchard, C., \&, Rhéaume, J., \& Ladouceur, R. (1999). Responsibility and perfectionism in OCD: an experimental study. Behavioral Research and Therapy, 37, 239-248.

Borloti, E. (2004). As relações verbais elementares e o processo autoclítico. Revista Brasileira de Terapia Comportamental e Cognitiva, 6(2), 221-236.

Braam, C., \& Malott, R. W. (1990). „I'll do it when the snow melts.“ The effects of deadlines and delays on rule-governed behavior. The Analysis of Verbal Behavior. 8, 67-76.

Catania, A. C. (1999). Aprendizagem: comportamento, linguagem e cognição (D. G. Souza, Trans.). Porto Alegre: Artes Médicas (Original work published 1998).

Catania, A. C. (2003). Verbal governance, verbal shaping and attention to verbal stimuli. In K. A. Lattal \& P. N. Chase (Eds.), Behavior Theory and Philosophy (pp. 301-321). New York: Plenum Publishers.

Catania, A. C., Matthews, B. A., \& Shimoff, E. (1982). Instruct versus shaped human verbal behavior: interactions with nonverbal responding. Journal of the Experimental Analysis of Behavior, 38(3), 233-248.

De Rose, J. C. (1999). O que é um skinneriano? Uma reflexão sobre mestre, discípulos e influência intelectual. Revista Brasileira de Terapia Comportamental e Cognitiva, 1, 67-74.

Hübner, M. M. C. (2003). Comportamento verbal e não verbal: efeitos de reforçamento de tactos com autoclíticos referentes ao ler sobre o tempo dispendido com leitura. In H. M. Sadi \& N. M. Castro (Eds.), Ciência e comportamento: conhecer e avançar (pp. 163-173). Santo André: ESETec.

Hübner, M. M., Austin, J., \& Miguel, C. F. (2008). The effects of praising qualifying autoclitics on the frequency of reading. The Analysis of Verbal Behavior, 24, 55-62. 
Ladouceur, R., Rhéaume, J., Freeston, M. H., Aublet, F, Jean, K., Lachance, S. Langlois, F., \& De Pokomandy-Morin, K. (1995). Experimental manipulations of responsibility: an analogue test for models of obsessive-compulsive disorder. Behavioral Research and Therapy, 8, 937-946.

Ladouceur, R., Léger, E., Rhéaume, J., \& Dubé, D. (1996). Correction of inflated responsibility in treatment of obsessivecompulsive disorder. Behavioral Research and Therapy, 34, 767-774.

Ladouceur, R., Rhéaume, J., \& Aublet, F. (1997). Excessive responsability in obsessional concerns: a fine-grained experimental analysis. Behavioral Research and Therapy, $35,423-427$.

Lloyd, K. E. (2002). Suggestions of correspondence training: suggestions for a revival. The Behavior Analyst, 25, 57-73.

Lopatka, C., \& Rachman, S. (1995). Perceived responsibility and compulsive checking: an experimental analysis. Behavioral Research and Therapy, 33(6), 673-684.

Malott, R. W. (1988). Rule-governed behavior and behavioral anthropology. The Behavior Analyst, 11, 181-203

Malott, R. W. (1989). The achievement of evasive goals controlled by rules describing contingencies that are not direct-acting. In S. C. Hayes (Ed.), Rule governed-behavior: cognition, contingencies, and instructional control (pp.269-322). New York: Plenum.

Mancini, F., D’Olimpio, F., \& Cieri, L. (2004). Manipulation of responsibility in non-clinical subjects: does expectation of failure exacerbate obsessive-compulsive behaviors? Behavioral Research and Therapy, 42, 449-457.

Matos, M. A. (2001). Comportamento governado por regras. Revista Brasileira de Terapia Comportamental e Cognitiva, 3(2), 51-66.

Michael, J. (1982). Distinguishing between discriminative and motivational functions of stimuli. Journal of Experimental Analysis of Behavior, 37, 149-155.

Michael, J. (1993). Establishing operations. The Behavior Analyst, $33,401-410$.

Michael, J. (2000). Implications and refinements of establishing operations. Journal of Applied Analysis of Behavior, 33, 401-410.

Mistr, K. N., \& Glenn, S. (1992). Evocative and function-altering effects of contingency-specifiyng stimuli. The Analysis of Verbal Behavior, 10, 11-21.
Rachman, S. (2002). A cognitive theory of compulsive checking. Behavioral Research and Therapy, 40, 625-639.

Reitman, D., \& Gross, A. (1996). Delayed outcomes and rulegoverned behavior among noncompliant" and "compliant" boys: a replication and extension. The Analysis of Verbal Behavior, 13, 65-77.

Salkovskis, P. M. (1995). Cognitive-behavioral approaches to the understanding of obsessional problems. In R. M. Rapee (Ed.), Current controversies in the anxiety disorders (pp. 103-133). London: Guilford.

Salkovskis, P. M., Richards, H. C., \& Forrester, E., (1995). The relationship between obsessional problems and intrusive thoughts. Behavioral Research and Therapy, 23, 281-299.

Schlinger, H., \& Blakely, E. (1987). Function-altering effects of contingency-specifying stimuli. The Behavior Analyst, 10, 41-45.

Sidman, M. (2001). Coerção e suas implicações (M. A. Andery \& T. M. Sério, Trans.). Campinas: Livro Pleno (Original work published in 1989).

Skinner, B. F. (1968). Science and human behavior. New York/ London: Free Press/Collier Macmillan (Original work published in 1953).

Skinner, B. F. (1976). About behaviorism. New York: Vintage Books (Original work published in 1974).

Skinner, B. F. (1992). Verbal behavior (Definitive edition). Acton, MA: Copley Publishing Group (Original work published in 1957).

Zamignani, D. R. (2001). Uma tentativa de entendimento do comportamento obsessivo-compulsivo: algumas variáveis negligenciadas. In R. C. Wielenska (Ed.), Sobre comportamento e cognição. Questionando e ampliando a teoria e as intervenções clínicas em outros contextos (pp. 247-256). Santo André: ESETec. 